\title{
The Problems and Countermeasures of Cathodic Protection Accepatnce of The Yili River Crossing by Horizontal Directional Drilling Method
}

\author{
Wei FU \\ China Petroleum Pipeline Engineering Corporation \\ Langfang City, Hebei Province, China \\ e-mail:59757383@qq.com
}

\author{
Xiang-Yu ZHENG \\ CPP Material \& Equipment Corporation \\ Langfang City, Hebei Province, China \\ e-mail: zhengxiangyu@cnpc.com.cn
}

\author{
Zhi-Ling ZHENG,Yu-Zhao LIAO,Jian-Jun LI,Sha-Sha CHEN \\ China Petroleum Pipeline Engineering Corporation \\ Langfang City, Hebei Province, China \\ e-mail: zhangzhiling@cnpc.com.cn,liaoyuzhao@cnpc.com.cn,lijianjun@cnpc.com.cn, chenshasha@cnpc.com.cn
}

\begin{abstract}
This paper aims at the problems and countermeasures of cathodic protection acceptance of the Yili River crossing project by horizontal directional drilling (HDD) method, addressing the performability of the acceptance criteria using polarization potential offset of not less than $0.7 \mathrm{~V}$ required by the Kazakhstan Owners. Polarization potential and depolarization potential measurements as well as coating resistance measurements have been carried out based on the methods and requirements specified in NACE and ISO standard. The results show that protection coating has been damaged in the process of the HDD implement and cathodic protection system can protect the steel exposed, and that the polarization potential offset of not less than $0.7 \mathrm{~V}$ required by the Owner cannot be met even the protection potential within the protection criteria specified in the design document. Finally, polarization potential offset of not less than $0.33 \mathrm{~V}$ has been agreed on by all parties for the acceptance of HDD pipe section.
\end{abstract}

Keywords-yili river; horizontal directional drilling crossing; cathodic protection

\section{INTRODUCTION}

By the end of August 2015, the total mileage of China's oil and gas pipeline has been more than $12 \times$ $10^{4} \mathrm{~km}$, whichhas promoted China's economic development and met the people's daily needs. However, China's energy is still shortage. The construction of China-Asian natural gas pipeline opens up a new international energy channel in the northwest of China, which will change the energy structure of the country, realize the diversification of natural gas import resources and fulfill the urgent need of China's economic development and people's lives.

China-Asian natural gas pipeline crosses the Yili River, the largest inland river in the middle of Asia, at the south of Zal, Kazakhstan. The Yili River crossing by horizontal directional drilling (HDD) becomes the most difficult unit project of construction of the natural gas pipeline in China-Asia, with the pipe section diameter of $1219 \mathrm{~mm}$, wall thickness of $27 \mathrm{~mm}$ and total length of $789.4 \mathrm{~m}$. And, meanwhile, the cathodic protection $(\mathrm{CP})$ for the external surface of HDD pipe sections has also gained focus.

\section{PIPELINE EXTERNAL CORROSION PROTECTION AND CATHODIC PROTECTION SCHEME}

According to GOST 51164 [1], the HDD pipe sections for the Yili River crossing shall be coated with three layer polyethylene coating (3LPE) consisting of epoxy powder primer and middle layer adhesive and PE top layer, with minimum total thickness of $3.7 \mathrm{~mm}$. A special heat shrinkage tape coupling with a manufacturer of primer and cross protection tape was used as filed joint coating system for girth weld. Impressed current cathode protection (ICCP) system comprised with cast-iron anodes as auxiliary anode for anode ground bed was used for buried main pipeline including the HDD pipe sections.

\section{CATHODIC PROTECTION PROBLEMS}

The CP problems which has been focused on is that the polarization potential offset of the cathodic protection of the pipeline should not be less than $0.7 \mathrm{~V}$ as per the requirements of Owner from Kazakhstan Republic, the program control documents compiled by the project management department, where the polarization potential offset means the difference value between instant off protection potential and natural corrosion potential of the underground steel pipeline. And the acceptance criteria required by Engineer is also based on this polarization potential offset not less than $0.7 \mathrm{~V}$. However, if so, the instant off protection potential of $-1.228 \mathrm{~V}$ can be approval and accepted, which is conflict with- $0.85 \mathrm{~V}$ to $-1.15 \mathrm{~V}$ protection potential criteria specified in cathodic protection design document provisions [3]. Obviously, to some extent, there is some problem about documents establishment. 


\section{SOLUTIONS}

\section{A. Measurment quipment}

- $\quad$ Polarization potentials measurement device ORION IP-01, manufacturer No. 2873.

- Polarization potentials measurement device ORION IP-01, manufacturer No. 2675.

- Polarization potentials measurement device IPP-1, manufacturer No. 342.

- Multi-meter UT 105, manufacturer No. 3090468444.

- Multi-meter UT 50 C, manufacturer No. 3110135424.

- Multi-meter AKTАKOM АТК-2021, manufacturer No. 11250244.

B. Devices

- Cathodic protection station CPS-5-02, manufacturer No. 85112 .

- Temporary anode grounding devices (steel pipe of $108 \mathrm{~mm}$ in diameter)

- Connection cables VVG $2 \times 10$.

- Adjustable resistors 0,004Ohm -50kOhm.

C. Equations

- Pipeline longitudinal resistance

$$
R_{T}=\frac{\rho_{m}}{\pi \times\left(D-\delta_{m}\right) \times \delta_{m}}
$$

where:

$\rho_{m}-$ Specific electrical resistance, $\mathrm{Ohm} \cdot \mathrm{m}$.

$D_{m}$ - Diameter, $\mathrm{m}$.

$\delta_{m}-$ Wall thickness, $\mathrm{m}$.

$$
\begin{aligned}
R_{T} & =\frac{2.45 \times 10^{-7}}{3.14 \times(1.219-0.027) \times 0.027} \\
& =2.45 \times 10^{-6} \mathrm{Ohm} / \mathrm{m}
\end{aligned}
$$

- $\quad$ Pipeline current spreading resistance

$$
R_{\mathrm{p}}=\frac{\rho_{\mathrm{m}} \times D}{2} \times \ln \frac{0.4 \times R_{p}}{D^{2} \times H \times R_{t}}
$$

where:

$\rho_{m}$-Specific electrical resistance, $\mathrm{Ohm} \cdot \mathrm{m}$; $D$-Diameter, m;

$$
\begin{aligned}
R_{\mathrm{p}} & =\frac{20 \times 1.219}{2} \times \ln \frac{0.4 \times 200}{1.129^{2} \times H 2.45 \times 10^{-6}} \\
& =197 \mathrm{Ohm} \bullet \mathrm{m}^{2}
\end{aligned}
$$

- Current value

$$
I=\frac{\pi \times D \times L \times U_{T .3}}{R_{\eta 3}+R_{p}}
$$

where: section, $\mathrm{V}$ $\mathrm{Ohm} \cdot \mathrm{m}^{2}$.

$U_{T .3}-$ Standardized potential offset at the end of the

$$
R_{\eta 3} \text {-Required resistance of protection coating, }
$$

$L$ - Length of the protected section, $\mathrm{m}$.

$$
I=\frac{3.14 \times 1.219 \times 789.4}{3 \times 10^{5}+197}
$$

$$
=0.007
$$

- Current density forprotected section

$$
j=\frac{I}{\pi \times D \times L}
$$

where:

$I$ - Cathodic polarization current, A.

$L$ - Length of the protected section, $\mathrm{m}$.

$$
\begin{aligned}
j & =\frac{0.015}{3.14 \times 1.219 \times 789.4} \\
& =0.00000496 \mathrm{~A} / \mathrm{m}^{2}
\end{aligned}
$$

- Insulation resistance of the protected section

$$
R_{N 3}=\frac{U}{J}-R_{p}
$$

where:

$U$ - Potential offset value.

$$
\begin{aligned}
R_{N 3} & =\frac{0.377}{0.00000496}-197 \\
& =75811 \mathrm{Ohm} \bullet \mathrm{m}^{2}
\end{aligned}
$$

\section{RESUlTS AND Discussions}

According to the engineering design, the most reliable coat was chosen for horizontal directional drilling crossing pipeline at that time. As is well-known, the anticorrosion coating system is a one-time project when used for HDD. X.C.Ma et al [4] and J.Quan et al [5] point out that the damage of the corrosion protection coating caused during HDD back-pull cannot be repaired in the process of implement of and after the completion of HDD project.

Based on previous engineering experience, the steel exposed to soil at coating damage can be protected by the supplementary cathodic protection system. The 3LPE insulation resistance specified in the design code of the Kazakhstan standards should be greater than $3 \times 10^{5} \mathrm{Ohm} \cdot \mathrm{m}^{2}$. But the test insulation resistance value from Supervision Engineer is $75811 \mathrm{Ohm} \cdot \mathrm{m}^{2}$, which indicates the corrosion protection coating has been damaged $n$ the process of HDD crossing, and thus, obviously, that the 3LPE insulation resistance value cannot meet the standard requirements. Furthermore, the impossibility of protection coating for HDD pipe section repair put it into a dilemma.

Supervision Engineer have been eventually persuaded to carry out the cathodic polarization and depolarization test and costing resistance measurement based on the measurement methods and requirements specified in NACE standard[2] and ISO standard[3] and thumb rule of project practice. Detailed test results are shown in Table I- Table III. 
TABLE I $\quad$ PROTECTIVE COATING CONDITIONCONTROL RESULTS (AVERAGE NATURE POTENTIAL $-0.528 \mathrm{~V}$ )

\begin{tabular}{|c|c|c|c|c|c|c|}
\hline № & $\mathbf{A}$ & $\mathbf{B}$ & $\mathbf{C}$ & $\mathbf{D}$ & $\mathbf{E}$ & $\mathbf{F}$ \\
\hline 1 & 3 & 7 & 0.45 & -0.749 & -0.823 & 0.295 \\
\hline 2 & 3 & 15 & 1.6 & -0.852 & -0.905 & 0.377 \\
\hline 3 & 3 & 20 & 2.3 & -0.891 & -0.943 & 0.415 \\
\hline 4 & 1 & 90 & 6.2 & -1.036 & -1.089 & 0.561 \\
\hline 5 & 1 & 200 & 13.2 & -1.129 & -1.178 & 0.65 \\
\hline 6 & 1 & 300 & 19.6 & -1.265 & -1.315 & 0.787 \\
\hline
\end{tabular}
A- Test time/h;
B- Polarization current $/ \mu \mathrm{A}$;
C- Power supply source output voltage/ V;
D- ON potential @HDD beginning/V;
E- ON potential@HDD end/V;
F- ON potential offset @HDD end/V

Results in Table I shows that, in the case of the natural corrosion potential $-0.528 \mathrm{~V}$, the potential offset at the HDD pipe section end increase with the increase of the polarization current imposed. The protection potential reaches $-1.178 \mathrm{~V}$ at polarization current of $200 \mu \mathrm{A}$, greater than $-1.15 \mathrm{~V}$ design criteria, with polarization potential offset of $0.65 \mathrm{~V}$, which, however, cannot meet the $0.7 \mathrm{~V}$ polarization potential offset required by the Owner. This indicates the design criteria and the Owner requirements are in contradiction.

TABLE II. POTENTIAL AFTER DEPOLARIZATION

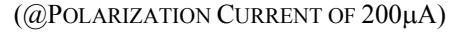

\begin{tabular}{|c|c|c|}
\hline № & Depolarization time & $\begin{array}{c}\text { Potential } \\
\text { @ HDD beginning/ V }\end{array}$ \\
\hline 1 & $\begin{array}{c}\text { At the moment of the power } \\
\text { supply source shutdown. }\end{array}$ & -0.79 \\
\hline 2 & After 15 minutes & -0.745 \\
\hline 3 & After 25 minutes & -0.718 \\
\hline 4 & After 35 minutes & -0.702 \\
\hline 5 & After 45 minutes & -0.694 \\
\hline 6 & After 55 minutes & -0.682 \\
\hline 7 & After 75 minutes & -0.667 \\
\hline 8 & After $24 \mathrm{~h}$ & -0.538 \\
\hline
\end{tabular}

Results in Table II shows that, when the polarization current is $200 \mu \mathrm{A}$ and then is switched off to depolarize, the pipe-to-soil potential decreases from $-0.79 \mathrm{~V}$ to $-0.667 \mathrm{~V}$ at 75 minutes after the depolarization, which indicates that the depolarization time is not sufficient to make the depolarization potential down to natural corrosion potential. By increase the depolarization time to more than $24 \mathrm{~h}$, the pipe-soil-potential of $-0.538 \mathrm{~V}$ obtained means that cathodic depolarization has been almost completed.

It shows in Table III that, the coating resistance of HDD pipe sections decreases as polarization current increases. Comparing the maximum coating resistance of 75811 $\mathrm{Ohm} \cdot \mathrm{m}^{2}$ measured to the coating resistance of $3 \times 10^{5}$ $\mathrm{Ohm} \cdot \mathrm{m}^{2}$ required by Kazakhstan standards, it is obviously that the coating resistance has sharp decreased at orders of magnitude. This result corresponds to engineering practice.

TABLE III. COATINGRESISTANCE OF PROTCTEDPIPESECTION AT DIFFERENT POLARIZATION CURRENT VALUES

\begin{tabular}{|c|c|c|c|c|}
\hline № & $\begin{array}{c}\text { Polarization } \\
\text { current/ } \boldsymbol{\mu A .}\end{array}$ & $\begin{array}{c}\text { Current } \\
\text { density/A/ } \mathbf{m}^{2}\end{array}$ & $\begin{array}{c}\text { Potential } \\
\text { offset/V }\end{array}$ & $\begin{array}{c}\text { Coating } \\
\text { resistance/ } \\
\text { Ohm· } \mathbf{m}^{2}\end{array}$ \\
\hline 1 & 15 & 0.00000496 & 0.377 & 75811 \\
\hline 2 & 20 & 0.0000066 & 0.415 & 62682 \\
\hline 3 & 90 & 0.0000298 & 0.561 & 18628 \\
\hline 4 & 200 & 0.000066 & 0.65 & 9848 \\
\hline
\end{tabular}

\section{CONCLUSIONS}

The protection coating has been damaged during the HDD back-pull concluded from the coating resistance measurements. Impressed current cathodic protection system can protect the steel exposed at the coating damage.

The polarization potential offset of not less than $0.7 \mathrm{~V}$ required by the Owner cannot be met, which, otherwise, is apt to tend to make the protection potential beyond the range of the $-0.85 \mathrm{~V} \sim 1-.15 \mathrm{~V}$ protection potential criteria specified in cathodic protection design document provisions.

The polarization potential offset of not less than $0.33 \mathrm{~V}$ has been agreed on by all parties for the acceptance of HDD pipe section based on results of the measurements and the requirements of the NACE and ISO standards.

\section{REFERENCES}

[1] GOST 51164-2005,Steel main pipelines.General requirements for corrosion protection[S].

[2] NACE SP 0169-2013, Control of External Corrosion on Underground or Submerged Metallic Piping Systems[S].

[3] ISO 15589-1-2003, Petroleum and natural gas industries-Cathodic protection of pipeline transportation systems - Part 1 On-land pipelines[S]

[4] X.C.Ma,S.W.Zhan, and Z.Chen, "Discussion on Anticorrosion Layer Protection at Pipeline Pullback Stage of Directional Drilling in China-Russia Heilongjiang Crossing Project,"Journal of petroleum Engineering Construction. vol. 36, Oct. 2010,pp.51-52.

[5] J.Quan,Q.L.Tan,L.W.Yuan,O.Y.Li,C.Zhang, "Detection and repair technology of external anticorrosive coating for buried oil and gas pipeline," Journal of Corrosion and Corrosion Protection. vol. 31, Feb. 2013, pp.75-77. 